Check for updates

Cite this: Mater. Adv., 2021

2, 1248

Received 6th November 2020,

Accepted 7th February 2021

DOI: $10.1039 / \mathrm{d} 0 \mathrm{ma} 00865 f$

rsc.li/materials-advances

\section{Atmospheric plasma deposition of bioinspired catechol-rich polymers: a promising route for the simple construction of redox-active thin films $\dagger$}

\author{
Abdelhafid Aqil, (D) a Farid Ouhib, (D) ${ }^{a}$ Christophe Detrembleur (D) *a and \\ Maryline Moreno-Couranjou (D ${ }^{b}$
}

In this communication, an atmospheric one-step plasma-based method is reported for the simultaneous synthesis and deposition of robust redox-active catechol-rich polymers. The bioinspired films are characterized by combining various analytical techniques, including IR, XPS, AFM and SIMS, and their potentials as organic cathode materials for lithium ion battery demonstrated. The influence of the coating thickness on the applicative properties of the films is also investigated.

Current energy-based demands related to the Internet of Things (IoT), including but not limited to active radiofrequency identification tags, sensors, smart clothes, or smart packaging, differ drastically from conventional batteries, thus highlighting the limitations of traditional Li-ion technology. ${ }^{1}$ Indeed, this field of applications requires thin films, which are ideally flexible, free of toxic and harmful metals, produced from abundant and possibly renewable resources, rapid-charging, and have an excellent life cycle, and efficient processing using roll-to-roll or similar processing techniques. Such characteristics have undeniably contributed to the development of organic polymer energy storage materials as sustainable alternatives to the well-established inorganic-based active components. ${ }^{2}$ If the absence of metal is an obvious first benefit in using polymericbased storage energy systems, the simplified mechanism based on simple redox reactions considerably broadens the nature and amount of suitable organic polymers, via a fine selection of the redox active groups, thus paving the way for high rate performances and long life cycles. ${ }^{3-5}$

Recently, catechol-bearing polymers emerged as important candidates for organic cathodes for energy applications in the

\footnotetext{
${ }^{a}$ Center for Education and Research on Macromolecules (CERM),

CESAM Research Unit, University of Liège, Sar-Tilman B6A, Liège, Belgium. E-mail: christophe.detrembleur@uliege.be

${ }^{b}$ Department of Materials Research and Technology, Luxembourg Institute of Science and Technology (LIST), Belvaux, Luxembourg

$\dagger$ Electronic supplementary information (ESI) available: Experimental protocols and supplementary characterizations. See DOI: 10.1039/d0ma00865f
}

works of Li on polydopamine ${ }^{6}$ and Detrembleur on synthetic polymers bearing pendant catechol groups. ${ }^{7}$ Ultra-robust redoxactive catechol-bearing polymer cathodes with unprecedented high cyclability, specific energy and power were constructed when carbon nanotubes were added as conductive fillers. ${ }^{7,8}$ Marcilla highlighted the potential of polymers bearing catechols for the conception of safe and sustainable water-based rechargeable batteries. ${ }^{9}$ In addition, Park reported on the combination of poly(vinyl catechol) cathode materials with single-ion conducting polymer nanoparticle electrolytes for designing all-solid state lithium organic batteries with excellent rate performances and a long life cycle. $^{10}$ Other relevant examples are illustrated elsewhere. ${ }^{11}$ These recent works highlight the huge potential of synthetic catechol-based polymers for battery applications. However these redox-active polymers have to be prepared - for the most part, following multistep procedures - prior to being processed as a cathode material. Therefore, the one-step synthesis and deposition of the polymer directly on the current collector via a straightforward and scalable process is highly desirable, but still remains unreported.

Recently, we reported on the abilities of a one-step atmospheric aerosol-assisted plasma polymerization method ensuring high deposition rates of high purity and pinhole-free extremely adherent and tunable catechol-bearing films in terms of morphology, thickness and catechol content. ${ }^{12,13}$ In particular, the developed approach offers an interesting alternative to the production of catechol-films from liquid-assisted plasma routes, ${ }^{14,15}$ known to suffer from non-wetting phenomena. Compared to the work of Mun et al. exploiting dopamine ${ }^{16}$ the method relies on injecting a liquid precursor consisting of a catechol-based vinyl monomer (dopamine (meth)acrylamide) dissolved in (di)methacrylate acting as co-monomer and solvent directly into the plasma discharge zone. Although the catechol-functionalized thin films were successfully exploited for the covalent immobilization of biomolecules, ${ }^{13}$ such a precursor formulation was irrelevant for energy storage applications due to the low catechol density diluted in the methacrylate-based film matrix. 
In this communication, we report the simple construction route of robust redox-active catechol-rich films, resulting from the combination of atmospheric aerosol-assisted plasma technology and macromolecular engineering. We also demonstrate that this redox-active film is promising for the construction of cathodes for energy applications, in this case, lithium ion battery as a proof of concept.

In order to maximize the theoretical capacity $\left(C_{\mathrm{th}}\right)$ of a polymeric cathode material, the content of atoms that are not redox-active should be as low as possible. Therefore, for this study, we selected 4-vinyl catechol, the smallest vinyl monomer bearing a catechol group, for the production of the polymerbased cathode. Another advantage of this monomer is its simple production at reasonable yield $(68 \%)$ by decarboxylation of caffeic acid, a natural catechol compound. As the monomer is a solid material in its pure state, it was used in solution in a volatile solvent (diethyl ether) (ESI, $\dagger$ section S2 and Fig. S1)

The solution of the monomer was injected into the AP-DBD system using an aerosol system, as illustrated in Scheme 1. The plasma polymerization was initiated under pulsed conditions with plasma $t_{\text {on }}$ and $t_{\text {off }}$ durations fixed at 1 and $30 \mathrm{~ms}$, respectively. Based on previous studies on other vinyl monomers, the polymerization was assumed to occur by a radical pathway, with the initiating radicals that are generated during $t_{\mathrm{on}}$ and the propagation that occurred during $t_{\text {off. }}{ }^{12,17}$

The chemistry of the plasma-deposited film was investigated by FT-IR analyses (Fig. 1a). To interpret the results easily, the monomer solution (precursor mixture) was also analysed as a reference. Due to fast solvent evaporation, the precursor spectrum mainly exhibited the characteristic vinyl catechol bands. Hence, UV and IR spectroscopies allowed to confirm the preservation of the catechol aromatic ring in the deposited film, with the presence of the catechol UV peak at $280 \mathrm{~nm}^{18}$ (ESI, $\dagger$ Fig. S2) and the presence of (i) the IR $\mathrm{C}=\mathrm{C}$ aromatic stretching bands located at 1608 and $1517 \mathrm{~cm}^{-1}$ (i.e., [C] and [D] bands; Fig. 1a) and the $\mathrm{C}-\mathrm{H}$ in a plane-substituted benzene band at $1182 \mathrm{~cm}^{-1}$ (i.e., $\left.[\mathrm{H}]\right)$ and (ii) catechol $\mathrm{OH}$ stretching and bending bands at $3376 \mathrm{~cm}^{-1}$ and $1368 \mathrm{~cm}^{-1}$, respectively (i.e., $[\mathrm{A}]$ and $[\mathrm{F}]$ bands) and $\mathrm{C}-\mathrm{C}-\mathrm{O}$

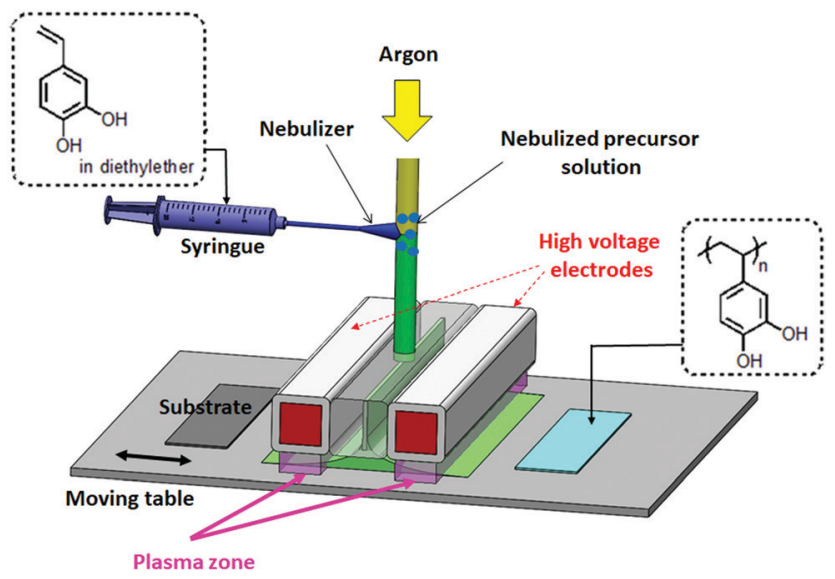

Scheme 1 Representation of the atmospheric pressure plasma process for the construction of poly(vinyl catechol) films.
[A] $[B][C][D][E][F][G][H]$
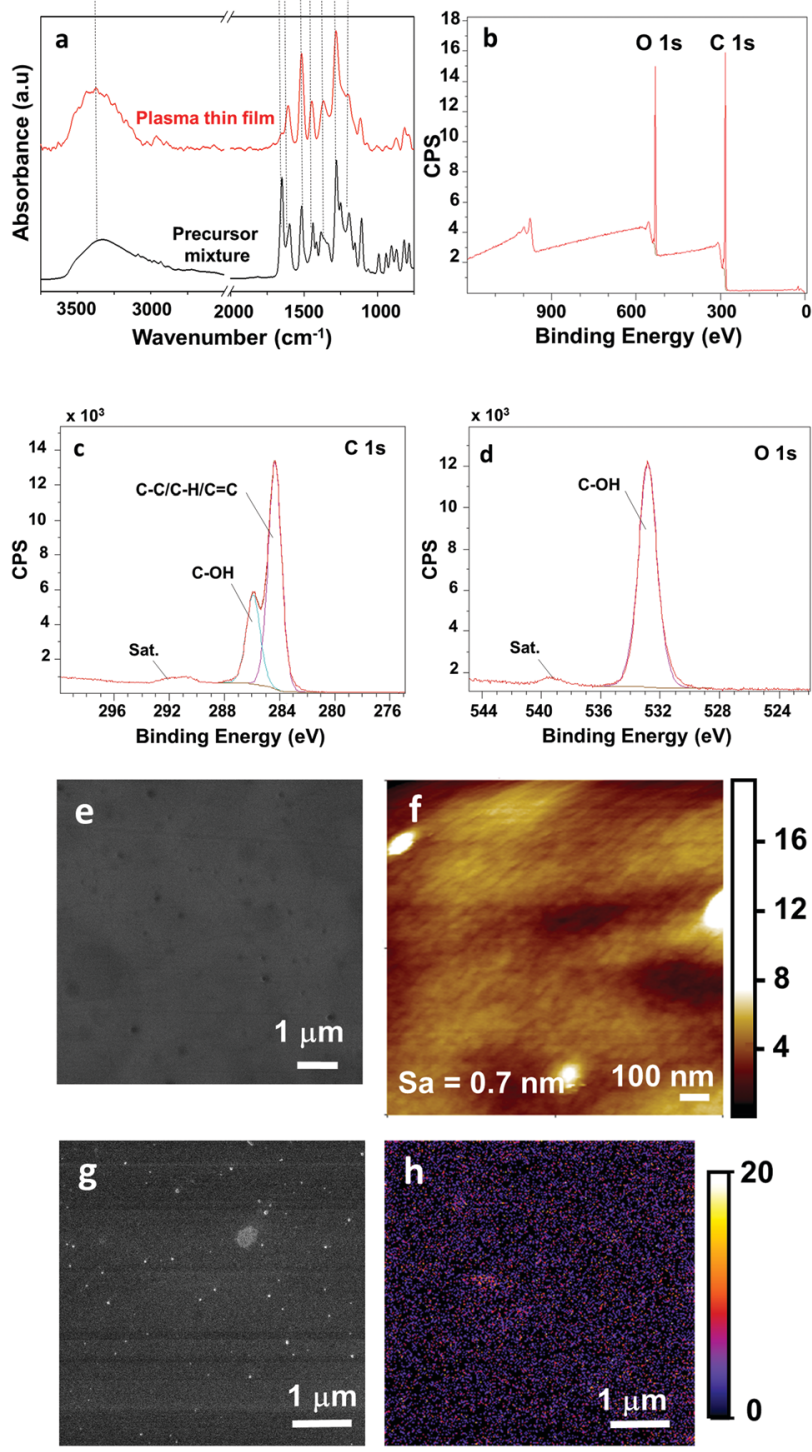

Fig. 1 Characterization of the plasma-deposited catechol-rich film. (a) Attenuated total reflectance-Fourier transform infrared (ATR-IR) absorption of the precursor mixture (black) and plasma-deposited film on mirror-polished stainless-steels (red), (b) XPS survey spectrum, (c) XPS $C$ 1s and (d) $O$ 1s curve fitting spectra, (e) HIM-SIMS picture of a coated mirror-polished stainless-steel, (f) AFM picture of the plasma-deposited film on a silicon wafer, HIM-SIMS pictures of (g) a plasma coating after $24 \mathrm{~h}$ immersion in an $\mathrm{AgNO}_{3}$ solution and (h) Ag surface distribution in purple.

stretching band at $1282 \mathrm{~cm}^{-1}$ (i.e., [G] band). In addition, the strong decrease and almost complete disappearance of the $\mathrm{C}=\mathrm{C}$ vinyl band located at $1650 \mathrm{~cm}^{-1}$ (i.e., [B]) suggested the consumption of the vinyl monomer by a free radical polymerization pathway. The aliphatic $\mathrm{CH}_{2}$-like polymer backbone was observed by the corresponding high band intensity at $1445 \mathrm{~cm}^{-1}$ (i.e., [E] band).

To gain insights into the surface chemistry of the coating, XPS analyses were carried out (Table S1, ESI, $\dagger$ and Fig. 1b-d). As shown in the XPS survey spectra (Fig. 1b), the film was mainly composed of $\mathrm{C}$ and $\mathrm{O}$. Interestingly, the absence of nitrogen in the deposited film suggested negligible air contamination 
during the synthesis within the open-air plasma process. In addition, the $\mathrm{C}: \mathrm{O}$ surface composition of the film was estimated at around $80: 20$ at $\%$, which is similar to the composition of a conventional poly(vinyl catechol) polymer. In accordance with IR analyses, the XPS C1s and O1s curve fittings confirmed a film mainly composed of catechol functionalities, notably with the detection of the $\pi-\pi^{*}$ satellites peaks, characteristics of the conjugated bonds (vinyl and aromatic carbon ring) and located at 291.6 and $539.4 \mathrm{eV}$, respectively. In addition, the carbon contributions, detected at 284.3 and $285.9 \mathrm{eV}$, indicated that the carbon element was mainly involved in saturated $\mathrm{C}-\mathrm{C} / \mathrm{C}-\mathrm{H}$ and aromatic bonds and catechol bonds at $70.7 \%$ and $29.3 \%$ of the C1s peak, respectively. Such results are fully in agreement with the O1s curve fitting results highlighting a single oxygen contribution at $532.8 \mathrm{eV}$, related to the catechol functionality. Indeed, by considering the global quantification, the catechol contributions from the $\mathrm{C} 1 \mathrm{~s}$ and $\mathrm{O} 1 \mathrm{~s}$ were similar and of around 23.4 and 20.0 at $\%$, respectively.

Helium Ion Microscopy observations revealed the formation of homogeneous and pinhole-free thin films on the entire surface of the substrates with no noticeable crack (Fig. 1e). Atomic force microscopy (AFM) evidenced that the plasmadeposited thin films homogeneously covered the entire surface (Fig. 1f). In addition, the surface presented a low roughness (i.e., arithmetical mean roughness(Sa) around $0.7 \mathrm{~nm}$ ). Interestingly, the dynamic character of the plasma technique allowed the film thickness to be controlled easily considering the $0.26 \mathrm{~nm} \mathrm{~s}^{-1}$ deposition rate. Indeed, the substrates to be treated being directly placed onto the moving table, the production of coatings with controlled thicknesses was achieved via the direct and simple implementation of the number of cycles of the table moving under the plasma discharge zone.

In order to roughly estimate the distribution of the catechols in the plasma-deposited film, the Helium Ion Microscope Secondary Ion Mass Spectroscopy (HIM-SIMS) technique was exploited. As-deposited film (used as reference; Fig. 1e) and coated surfaces after $24 \mathrm{~h}$ immersion in a silver salt solution (Fig. 1g) were firstly examined. The goal of immersing the catechol functionalized surface in a silver nitrate solution was to evidence the formation of silver particles by the reduction of the silver cations by catechols. ${ }^{18-20}$ This experiment will indirectly prove the presence of catechols at the surface of the substrate. Hence, two distinct surfaces were observed with, notably, the appearance of rounded shape particles for the immersed surfaces, that might be attributed to silver nanoparticle $\left(\mathrm{Ag}^{0} \mathrm{NPS}\right)$. By combining HIM-SIMS surface imaging and silver analytical mapping (Fig. 1h) pictures, one can clearly observe the dense and homogeneous distribution of silver elements (in purple) covering the entire substrate surfaces, suggesting an homogeneous distribution of the catechols in the film.

The potential of the plasma-deposited poly(vinyl catechol) thin film as a cathode material for electrochemical energy storage systems was studied in a coin-type half-cell configuration compared to lithium counter/reference electrodes with lithium bis(trifluoromethanesulfonyl)imide (LiTFSI) in a mixture of tetraglyme (G4) and ethyl methyl carbonate (EMC) (G4 : EMC =
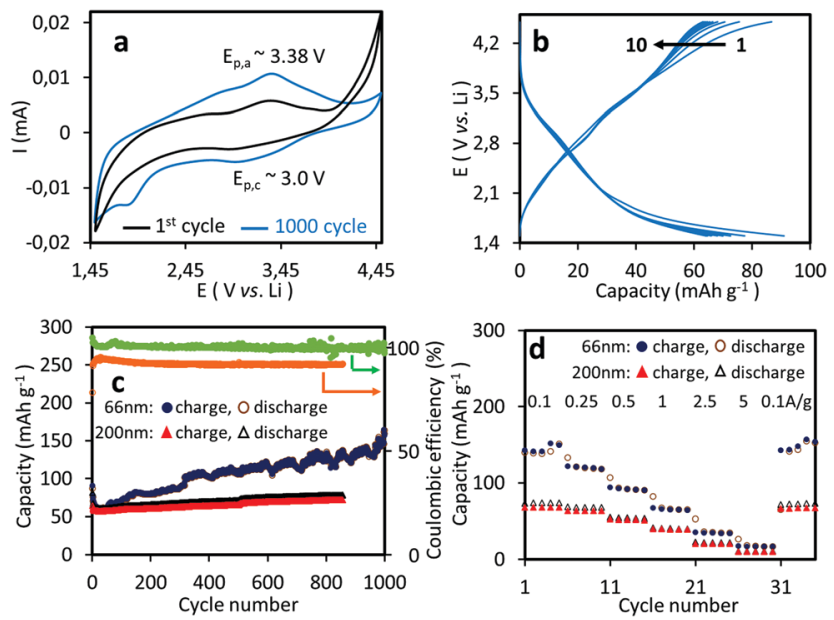

Fig. 2 Electrochemical performance of the plasma-deposited poly(vinyl catechol) film (thickness $=66 \mathrm{~nm}$ ). (a) Cyclic voltammetry (CV) curves at a scan rate of $0.1 \mathrm{mV} \mathrm{s}^{-1}$; (b) ten first charge-discharge curves at the current density of $0.1 \mathrm{~A} \mathrm{~g}^{-1}$. (c) Cycling stability of the electrodes at the current density of $0.1 \mathrm{~A} \mathrm{~g}^{-1}$ over 1000 cycles. (d) Rate performance of the electrodes at different current densities from 0.1 to $5 \mathrm{~A} \mathrm{~g}^{-1}$.

$1: 2, \mathrm{v} / \mathrm{v})$ as the electrolyte. This electrolyte was selected as it had been demonstrated to be optimal for catechol-bearing polymer cathodes. ${ }^{7,8}$ Importantly, the proof-of-concept experiments were carried out on a poly(vinyl catechol) thin film that did not contain a conductive filler (i.e. carbon nanotubes or carbon black) and was deposited on stainless steel disks (see Experimental section for details).

First, the cyclic voltammogram (CV) was recorded at a scan rate of $0.1 \mathrm{mV} \mathrm{s}^{-1}$ in a voltage range of between 1.5 and $4.5 \mathrm{~V}$ ( $v s$. $\left.\mathrm{Li}^{+} / \mathrm{Li}\right)$. The $\mathrm{CV}$ profile shows broad redox peaks centred at a cathodic potential $\left(E_{\mathrm{p}, \mathrm{c}}\right)$ of about $3.0 \mathrm{~V}$ and at an anodic potential $\left(E_{\mathrm{p}, \mathrm{a}}\right)$ of $3.38 \mathrm{~V}$, corresponding to the reduction of the quinone groups and reoxidation of the dilithium catecholates in poly(vinyl catechol), respectively (Fig. 2a). These cathodic and anodic potentials were close to those measured for the poly(vinyl catechol) prepared by the radical polymerization of $\mathrm{VC}$ and loaded by $\operatorname{CNTs}\left(E_{\mathrm{p}, \mathrm{c}}=2.9 \mathrm{~V}\right.$ and $\left.E_{\mathrm{p}, \mathrm{a}}=3.5 \mathrm{~V}\right)$,pointing out that the redox properties of catechol were preserved during the plasma deposition process. ${ }^{7}$

Galvanostatic charge-discharge (GCD) experiments were carried out to evaluate the charge storage capabilities of the thin polymer film. The resulting charge-discharge curves (Fig. 2b) provide different characteristic values toward the performances of the material. First, the sloping voltage profile of the galvanostatic curves over the entire potential range reflected the common cycling behavior of the quinone groups with the presence of the slope voltage plateau at approximately +2.9 and $+3.5 \mathrm{~V} v$ s. $\mathrm{Li}^{\prime} / \mathrm{Li}^{+}$, respectively, which is consistent with CV results (Fig. 2b). Furthermore, the initial specific capacity (calculated with respect to the used amount of active material) of the battery determined in a straightforward manner from the observed charging time and the applied current is $90 \mathrm{~mA} \mathrm{~h} \mathrm{~g}{ }^{-1}$. It is important to note that the slight decrease in the discharge capacity observed during the initial few cycles (10-20) corresponds 
to the activation period required for converting the catechols into quinones. Moreover, the Coulombic efficiency close to $100 \%$ of a charge/discharge is an excellent indicator for the electrochemical reversibility of the redox process of quinone groups. Lastly, the development of the capacity and Coulombic efficiency over several charge/discharge cycles (Fig. 2c) allows an evaluation of the longterm capability of the materials which represents the so-called cycle life of the batteries.

To evaluate the influence of the plasma deposition time and thus the thickness of the plasma-deposited coating - on the electrochemical properties of the cathode, GCD experiments were conducted using two different film thicknesses $(66 \mathrm{~nm}$ and $200 \mathrm{~nm}$ ) over 850 to 1000 cycles at a $\mathrm{C}$ rate of $0.1 \mathrm{~A} \mathrm{~g}^{-1}$. The thinner film presented an initial discharge capacity of $90 \mathrm{~mA} \mathrm{~h} \mathrm{~g}^{-1}$ and surprisingly, after a few activation cycles, the specific capacity increased during cycling from $60 \mathrm{~mA} \mathrm{~h} \mathrm{~g}{ }^{-1}$ to $\sim 150 \mathrm{~mA} \mathrm{~h} \mathrm{~g}^{-1}$ (after 1000 cycles), reaching $\sim 40 \%$ of the theoretical capacity $\left(C_{\mathrm{th}}=372 \mathrm{~mA} \mathrm{~h} \mathrm{~g}^{-1}\right)$, with a coulombic efficiency close to $100 \%$ (Fig. 2c). This increase in discharge capacity during cycling suggested that increasing numbers of redox species were activated during cycling, presumably due to the progressive swelling of the polymer film by the electrolyte, thus enabling more and more redox species to be accessible and activated. ${ }^{21,22}$ The significant peak growth of the catechol redox couple in the CV profile performed after 1000 cycles clearly corroborated this hypothesis (Fig. 2a). The same trend was observed for the thicker film but in a much more moderate manner. The initial discharge capacity for the thicker film was lower $\left(64 \mathrm{~mA} \mathrm{~h}^{-1}\right)$ and increased slightly with the number of cycles to reach $72 \mathrm{~mA} \mathrm{~h} \mathrm{~g}^{-1}$ after 850 cycles, which corresponds to $\sim 20 \%$ of the theoretical capacity. The lower capacity measured for the thicker films was assumed to be the result of the insulating property of poly(vinyl catechol), which did not facilitate redox reactions when the film thickness was increased (due to poor electron conduction within the film). ${ }^{6,23}$

The power performance of the two films was then evaluated at different current rates from $0.1 \mathrm{~A} \mathrm{~g}^{-1}$ to $5 \mathrm{~A} \mathrm{~g}^{-1}$. Results are summarized in Fig. 2d. For the thinner film, a reversible capacity of $141 \mathrm{~mA} \mathrm{~h} \mathrm{~g}^{-1}$ was measured at low C-rate of $0.1 \mathrm{~A} \mathrm{~g}^{-1}$. The discharge capacities decreased monotonically as the C-rate increased, with satisfactory reversible capacities (and also retention) of 120 (85\%), 65 (46\%) and $35(25 \%) \mathrm{mA} \mathrm{h}^{-1}$ at $0.25,1$ and $2.5 \mathrm{~A} \mathrm{~g}^{-1}$, respectively. At $5 \mathrm{~A} \mathrm{~g}^{-1}$, the cell still delivered about $18 \mathrm{~mA} \mathrm{~h} \mathrm{~g}{ }^{-1}$ and we observed a nearly quantitative recovery of the initial capacity when the C-rate was shifted back to $0.1 \mathrm{~A} \mathrm{~g}^{-1}$, suggesting that no irreversible side reactions or degradation occurred during these experiments. The same trends were noted for the thicker film, albeit with lower capacities of 50 and $10 \mathrm{~mA} \mathrm{~h} \mathrm{~g}{ }^{-1}$ at 0.1 and $5 \mathrm{~A} \mathrm{~g}^{-1}$, respectively.

In summary, by combining atmospheric aerosol-assisted plasma technology and macromolecular engineering using 4-vinyl catechol monomer, easily obtained through the decarboxylation of natural caffeic acid, catechol-rich polymer films of tuneable thickness have been successfully synthesised and deposited on stainless steel. The potential of thin catecholbearing films as cathode materials in a half-cell configuration for LIBs was evaluated without using any conductive filler. The thinner film (66 nm) delivered a reversible capacity of $\sim 150 \mathrm{~mA} \mathrm{~h} \mathrm{~g}^{-1}$ after 1000 cycles at a $\mathrm{C}$ rate of $0.1 \mathrm{~A} \mathrm{~g}^{-1}$ and cycling up to $5 \mathrm{~A} \mathrm{~g}^{-1}$ was possible, albeit with a decrease of the discharge capacity. Increasing the film thickness decreased the discharge capacity as a result of the insulating property of the film, which did not favour electron conduction or, therefore, efficient redox reactions. Future research activities might focus on the optimization of the film properties. In this aim, the versatility of the aerosolassisted plasma deposition route offers the possibility to investigate the deposition of composite coating-containing fillers. Another research activity might rely on investigating the deposition of composite from a plasma-torch process. Indeed, such plasma process configuration ensures the local deposition of films onto virtually any substrates of any shape, thus paving the way for the construction of cathode materials requiring miniaturized devices.

We gratefully acknowledge the financial support of the National Fund for Scientific Research (F.R.S.-FNRS) and the Luxembourg National Research Fund (FNR) through the BIOREAFILM project (C15/MS/10365992/BIOREAFILM/Moreno). J. Guillot, J. N. Audinot and P. Grysan from LIST are acknowledged for insightful discussions and the acquisition of the XPS, HIMSIMS and AFM data, respectively.

\section{Conflicts of interest}

There are no conflicts to declare.

\section{Notes and references}

1 Y. Kabalci, E. Kabalci, S. Padmanaban, J. B. Holm-Nielsen and F. Blaabjerg, Electronics, 2019, 8(9), 972-988.

2 J. B. Goodenough and K. S. Park, J. Am. Chem. Soc., 2013, 135(4), 1167-1176.

3 S. Muench, A. Wild, C. Friebe, B. Häupler, T. Jonaschka and U. Schubert, Chem. Rev., 2016, 116(16), 9438-9484.

4 M. D. Hager, B. Esser, X. Feng, W. Schuhmann, P. Theato and U. S. Schubert, Adv. Mater., 2020, 32, 2000587-2000595.

5 L. Yong and C. Jun, Nat. Rev. Chem., 2020, 4(3), 127-142.

6 T. Liu, K. C. Kim, B. Lee, Z. Chen, S. Noda, S. S. Jang and S. W. Lee, Energy Environ. Sci., 2017, 10(1), 205-215.

7 N. Patil, A. Aqil, F. Ouhib, S. Admassie, O. Inganäs, C. Jérôme and C. Detrembleur, Adv. Mater., 2017, 29(40), 1703373-1703382.

8 (a) N. Patil, C. Jérôme and C. Detrembleur, Prog. Polym. Sci., 2018, 82, 34-91; (b) N. Patil, M. Aqil, A. Aqil, F. Ouhib, R. Marcilla, A. Minoia, R. Lazzaroni, C. Jérôme and C. Detrembleur, Chem. Mater., 2018, 30(17), 5831-5835.

9 N. Patil, A. Mavrandonakis, C. Jérôme, C. Detrembleur, J. Palma and R. Marcilla, ACS Appl. Energy Mater., 2019, 2(5), 3035-3041.

10 B. Kim, H. Kang, K. Kim, R. Y. Wang and M. J. Park, ChemSusChem, 2020, 13(9), 2271-2279.

11 Y. K. Jeong, S. H. Park and J. W. Choi, ACS Appl. Mater. Interfaces, 2018, 10(9), 7562-7573. 
12 V. Jalaber, D. D. Frari, J. D. Winter, K. Mehennaoui, S. Planchon, P. Choquet, C. Detrembleur and M. MorenoCouranjou, Front. Chem., 2019, 7, 883-894.

13 M. Moreno-Couranjou, J. Guillot, J. N. Audinot, J. Bour, E. Prouvé, M. C. Durrieu, P. Choquet and C. Detrembleur, Plasma Processes Polym., 2020, 17(7), 1900187-1900203.

14 R. Mauchauffé, S. Bonot, M. Moreno-Couranjou, C. Detrembleur, N. D. Boscher, C. Vandeweert, A.-S. Duwez and P. Choquet, Adv. Mater. Interfaces, 2016, 3(8), 1500520-1500525.

15 Z. Wang, C. Xu, Y. Lu, G. Wei, G. Ye, T. Sun and J. Chen, Polym. Chem., 2017, 8, 4388-4392.

16 M. K. Mun, Y. J. Jang, J. E. Kim, G. Y. Yeom and D. W. Kim, RSC Adv., 2019, 9, 12814-12822.

17 J. Friedrich, Plasma Processes Polym., 2011, 8(9), 783-802.
18 M. Yu, J. Hwang and T. J. Deming, J. Am. Chem. Soc., 1999, 121(24), 5825-5826.

19 H. Lee, J. Rho and P. B. Messersmith, Adv. Mater., 2009, 21(4), 431-434.

20 E. Faure, C. Falentin-Daudré, T. S. Lanero, C. Vreuls, G. Zocchi, C. Van De Weerdt, J. Martial, C. Jérôme, A.-S. Duwez and C. Detrembleur, Adv. Funct. Mater., 2012, 22(24), 5271-5282.

21 X. Dong, B. Ding, H. Guo, H. Dou and X. Zhang, ACS Appl. Mater. Interfaces, 2018, 10, 38101-38108.

22 Z. Man, P. Li, D. Zhou, R. Zang, S. Wang, P. Li, S. Liu, X. Li, Y. Wu, X. Liang and G. Wang, J. Mater. Chem. A, 2019, 7, 2368-2375.

23 A. Aqil, C. Jérôme, F. Boschini and A. Mahmoud, Batteries Supercaps, 2021, 4(2), 374-379. 